\title{
ESTUDOS
}

\section{Idades da vida, infância e a racionalidade médico-higiênica em Portugal e no Brasil (séculos 17-19)*}

António Gomes Alves Ferreira José G. Gondra

* Este artigo se constitui resultado parcial de estudos desenvolvidos no âmbito do Projeto "A Educação e sua Infância", no quadriênio 2002-2005, apoiado pela Capes (Brasil) e Grices (Portugal).

\section{Resumo}

Analisa os efeitos que a racionalidade médico-higiênica produziu no modo de compreender a vida e sua cronologia, com ênfase ao debate a respeito da infância. Para tanto, procura observar zonas de semelhança na circulação dessas representações em Portugal e no Brasil, ao longo dos séculos 17, 18 e 19. Assim permite pensar a produção de uma doutrina difundida internacionalmente, sob o manto da crença em uma razão redentora, que impacta de modo particular as diferentes instituições que são criadas para lidar de modo especializado com cada etapa da vida. Dentre elas, as formas escolares.

Palavras-chave: história da educação; história da infância; higiene.

\section{Abstract \\ Ages of life, infancy and the medical-hygienical rationality in Portugal and Brazil $\left(17^{\text {th }}-19^{\text {th }}\right.$ centuries)}

In this article, we analyze effects that the medical-hygienical rationality produced in the way we comprehend life and its chronology, with emphasis on the debate regarding infancy. Therefore, we tried to observe zones of similarity in the circulation of these representations in Portugal and Brazil, during the $17^{\text {th }}, 18^{\text {th }}$ and $19^{\text {th }}$ centuries. This study allows to think the production of a doctrine spread out internationally, under the mantle of the belief in a redeeming reason, that impacts, in particular, the different institutions that are created to deal with a specialized way with each stage of life. Amongst them, the schooling forms.

Keywords: history of education; history of infancy; hygiene.

Todas as crianças, exceto uma, crescem. (...)

Wendy sabe que teria que crescer.

A gente sempre tem consciência disto depois de dois anos.

Dois anos: isto é o começo do fim.

(Barrie, 1904)

A transcrição de Barrie é sedutora para quem gosta de imaginar uma infância plena de felicidade e que as agruras só vêm com o crescimento. Mas há, por certo, diferença entre ser criança e o ser que assim é percebido pelos adultos, sejam estes pessoas atentas ou até especialistas em algum dos domínios da ciência e que têm por objeto o estudo do desenvolvimento infantil. Se pais dedicados olham para o pequeno ser que geraram como uma projeção da felicidade que gostavam de sentir, médicos, psicólogos e docentes observam a criança a partir de critérios de desenvolvimento, 
encarando-a, sobretudo, a partir da noção de possibilidade. Para uns e para outros, a criança é fundamentalmente o que pode vir a ser ou mesmo o que deve vir a ser. A importância que é dada a sinais de crescimento e a manifestações diversas de desenvolvimento deriva menos de uma aceitação da felicidade do ser no momento e mais da avaliação do projeto em causa. A ansiedade posta no desen-volvimento tem sido compreendida por alguns como contrária à essência da infância. Mais do que dar relevo a exigências ditadas por um futuro delineado por outros, seria preciso aceitar a criança como alguém que tem direito a viver no seu mundo, um mundo em que a pressão do crescimento não existe, portanto, um mundo mágico que não pode ser terra de homens.

Terra do Nunca e Terra dos Homens. Com essa polarização, Barrie ${ }^{1}$ (1860-1937) constrói uma aventura fabulosa, opondo dois mundos. No primeiro não há relógios e a vida não é cronologizada. Já no segundo, a vida em suas diferentes dimensões é objeto de repartição, de classificação, de ordenação, isto é, submetida a determinadas racionalidades. Tal aventura pode ser lida em duas frentes articuladas: como crítica ao mundo em que os homens vivem e como sinal de como o mundo deveria ser. Nesse registro, é fábula, contendo uma prescrição muito definida, dirigida a reforçar uma descrição distinta do mundo dos adultos e do mundo das crianças. $\mathrm{O}$ clima mágico da aventura permite que as crianças da terra sem relógios desenvolvam atividades atribuídas aos adultos, exceção feita aos aspectos do trabalho e do sexo, sendo esses os elementos que distinguiriam os dois mundos, as duas idades. Assim, é para a "terra do nunca" que três irmãos (Wendy, John e Michael) que habitavam uma Londres urbanizada, civilizada e moralizada são carregados. A “terra do nunca” representa, pois, a utopia do lugar mais adequado para as crianças, no qual não se corria o risco de crescer e de perder o encantamento. Nessa narrativa, o elemento do mal, um pirata adulto, representa o risco e a disposição de eliminar o que não quer crescer, aquele que quer viver a infância em sua plenitude, como uma eternidade, se recusando a crescer e agir como um adulto, aventura que pode ser entendida como discurso articulado a outros que reivindica o reconhecimento da especificidade da infância, daquilo que seria o seu próprio, sua substância natural. Ao opor dois mundos, essa fábula termina por reforçar, de modo radical, a tese da vida repartida pelo critério da idade, o que até hoje é objeto de debate. ${ }^{2}$

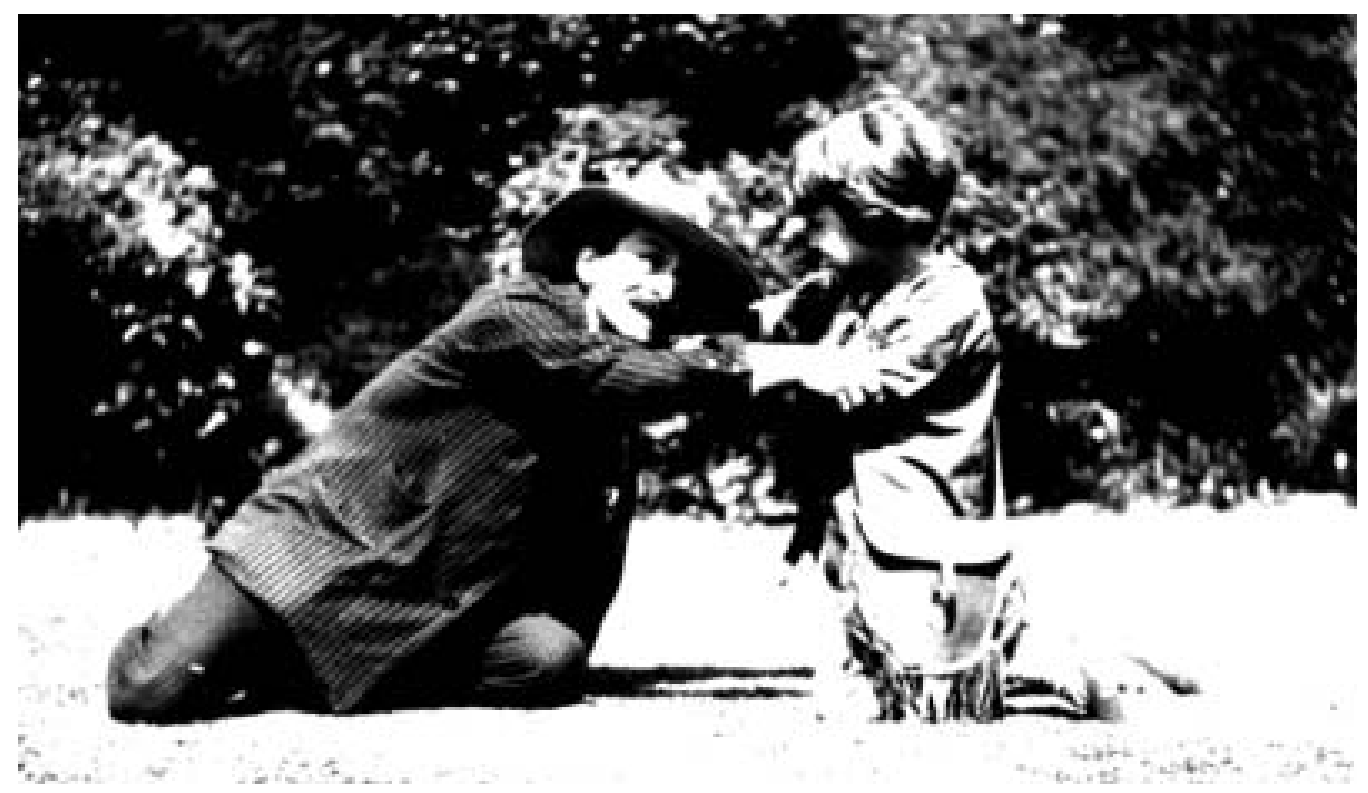

Figura 1 - Michael vestido como Peter Pan luta com J. M. Barrie como Capitão Gancho, em agosto de 1906
Trata-se do escocês James Matthew Barrie, autor da fábula Peter Pan - o menino que não queria crescer, na qual encena, em 17 capítulos, uma atitude de desencanto perante a vida adulta. Pode ser lida pelos traços da experiência desse autor, que passou por dramas significativos no plano pessoal (morte precoce de um dos 9 irmãos, morte da esposa, morte dos enteados...), e como crítica à Inglaterra, que respirava a tradição vitoriana de uma sociedade civilizada, ordenada, moralizada e cheia de etiquetas. A história de Peter Pan foi encenada pela primeira vez em 1904 e, a partir de então, conheceu grande sucesso, sendo transformada em livro (traduzido e adaptado para várias línguas), filme (uma primeira versão data de 1924 , os estúdios Disney fizeram a sua em 1954, teve uma para TV em 1976 , Steven Spielberg fez a sua em 1991, Hook - A Volta do Capitão Gancho, P. J. Hogan, em 2003 e, em 2004, por ocasião do centenário da peça, a própria vida do autor foi objeto do filme Em busca da Terra-do-Nunca, de Marc Forster) e inúmeras montagens teatrais em diferentes países. Para saber mais, acesse os endereços www.jmbarrie.co.uk e w w w.kirjasto.sci.fi/ jmbarrie.htm

O tema da infância na contemporaneidade tem dado margem a muitas reflexões. Recentemente, o jornal Folha de S. Paulo, em seu Caderno Mais, dedicou espaço privilegiado para essa reflexão. A esse respeito, cf. Marano (2005) e Katz e Freire (2005). 


\section{As idades da vida - natureza e cultura}

As idades da vida, por sua vez, vêm sendo descritas por meio de ciclos, etapas, momentos, fases, níveis, estágios e períodos. Esse léxico, apesar das diferenças que os termos guardam entre si, auxilia na construção da idéia de vida segmentada, aspecto que funciona como um ponto de articulação desse vocabulário. Tais termos remetem e reforçam a tese de que é possível, valendo-se de recursos variados, reconhecer aspectos comuns nas diferentes partes da cronologia da vida. É, portanto, no interior dessa crença que a idéia de infância vem sendo formulada e reproduzida, acoplada à criação e reordenação de instituições que passaram a ser estreitamente vinculadas à etapa "mais tenra da vida", como diria Fénelon, no final do século 17.

Nesse sentido, caberia indagar: o que há de mais homogêneo nessa "primeira idade" da vida? Responder a essa questão supõe estar atento para os critérios empregados na identificação dos seus traços comuns. Ariès, em seu conhecido trabalho, chama a atenção para os elementos da fantasia, tradição e exatidão que envolvem a inscrição de um novo ser no mundo civil: fantasia na escolha do nome, tradição no sobrenome e exatidão na definição das idades - exatidão que convive, segundo ele, com a heterogeneidade dos critérios adotados para descrever/compreender o desenvolvimento humano. Assim, a vida já foi repartida de acordo com o número de planetas, signos do zodíaco ou mesmo meses do ano, repartição e terminologia que nos parecem estranhas, mas que, à época, traduziam noções partilhadas pelos representantes da "ciência", correspondendo igualmente a um sentimento popular e comum da vida (Ariès, 1981, p. 38).

Com a popularização das "idades da vida", indicada pela iconografia e outras fontes consultadas por Ariès, estas passaram a ser associadas não apenas a etapas biológicas, mas também às funções sociais. Para esse autor, a repetição das imagens pregadas nas paredes, ao lado dos calendários e entre objetos familiares, alimentava a idéia de uma vida dividida em etapas bem delimitadas, correspondendo a modos de atividade, tipos físicos, funções e às modas do vestir. Desse modo, o pesquisador francês assinala que a periodização da vida tinha a mesma fixidez que o ciclo da natureza ou a organização da sociedade (p. 40), a despeito de uma proliferação nas formas de designar as idades. ${ }^{3}$

Embora o debate sobre o assunto pareça ter perdido sentido em face das conturbadas sociedades emergentes da desagregação do Império Romano, certo é que, a partir de finais da Idade Média, ele volta a ganhar crescente visibilidade na iconografia e nos discursos dos séculos seguintes. Do século 16 para o século 17, parece ter-se acentuado o apetite pela arrumação dos percursos em determinadas idades. No século 17 encontram-se já alguns livros impressos em língua portuguesa que se referem à problemática das idades da vida. Em um deles, o título, Vida espiritual do homem, conferida com as 6 idades da vida temporal, ${ }^{4}$ expressa logo uma opção etária que é diferente da apresentada por Francisco da Silva em um capítulo significativamente intitulado "Como a vida do homem he repartida em dez idades, e quaes são; e o mesmo dos Reynos, e Imperios". ${ }^{5}$ Mas se, à primeira vista, só vemos desfasamentos entre estes dois títulos, ambos refletem a mesma concepção unitária do mundo, tão freqüente nessa época, e a mesma preocupação de categorizar o desenvolvimento do indivíduo (Ferreira, 2000).

Todavia, na centúria de seiscentos, as mais interessantes abordagens sobre as idades em relação com a educação foram escritas por Coménio. Na Didáctica Magna, obra especialmente dedicada à arte de ensinar por "todo o tempo da juventude", admite que o período de crescimento pode ser dividido em quatro partes de seis anos cada, "infância, puerícia, adolescência e juventude" (Coménio, 1985, p. 410) e associa a cada uma delas uma escola peculiar, de modo que o regaço materno fosse a escola da infância, a escola primária fosse a escola da puerícia, a escola de latim ou o ginásio fosse a escola da adolescência, a academia fosse a escola da juventude. Mais tarde Coménio voltaria a dar relevo ao assunto das idades na Pampaedia, quarta parte de De Rerum Humanarum Emendatione Consultatio Catholica, onde disserta acerca da educação ao longo da vida e, por isso, aí já apresenta escolas adequadas a sete idades em que divide a vida humana, "das quais 
a primeira compreende a concepção e a gestação no útero materno; a segunda, o nascimento e, conseqüente a este, a infância; a terceira, a puerícia; a quarta, a adolescência; a quinta, a juventude; a sexta, a idade adulta; a sétima, a velhice” (Coménio, 1971, p. 110). O mais interessante é que ele sublinha a importância de cada uma destas idades como fases especialmente convenientes a determina-das aprendizagens, como diz: "para a realização daquelas coisas para que foi apta a primeira idade, não o será a segunda, muito menos a terceira” (p. 109). Ora, o que o pedagogo tcheco faz com mestria é, precisamente, apresentar uma organização educacional que tem como eixo a sua concepção das idades da vida. Mas a notável proposta pedagógica que apresenta nos trabalhos mencionados não deixa, no entanto, de seguir uma compreensão do percurso da vida que vinha fundamentando a definição de normas de regulação social.

Tal como acontece hoje, as idades constituíam um referencial de desenvolvimento que era tido em consideração nas disposições normativas estipuladas por entidades de grande poder regulador. Não admira, por isso, que o ritmo da sociabilização se processasse em torno delas, as quais delimitavam capacidades e responsabilidades e condicionavam o desenrolar da vida de cada um, a ponto de determinar alterações de estatuto com o simples saltar de degrau etário. Por exemplo, só a partir dos 12, 14 anos, os órfãos tinham direito a receber soldada fixada por lei, ainda que a partir dos 7 pudessem ser dados a quem pagasse a melhor (Ferreira, 2000). Na verdade, os 12, 14 anos, conforme se considerasse o sexo feminino ou masculino, davam acesso a um estatuto superior e, simultaneamente, a uma responsabilização maior. A partir dessa idade tornava-se possível o casamento, era obrigatória a comunhão anual na Quaresma, podiase escolher livremente a sepultura, o que era substancialmente diferente do definido para o período anterior, que começava aos 7 anos, para o qual se estipulava um número inferior de ofícios fúnebres, a possibilidade de apenas fazer "esponsais de futuro" e se estava só obrigado à confissão anual (Ferreira, Pereira, 1987).

As idades pareciam também um instrumento analítico interessante para os médicos. Ao longo do século 18, várias são as obras médicas de língua portuguesa que têm em consideração as idades. Um dos que se debruçou sobre o assunto na primeira metade de setecentos foi Rodrigues de Abreu, que apresentou e descreveu na sua Historiologia medica as diversas idades tendo em conta a sucessão de fenômenos físicos inerentes ao desenvolvimento do corpo. Na sua opinião, as principais idades eram a infância, a puerícia, a adolescência, a juventude, a viril, a consistente e a velhice verde, meia e decrépita. A infância compreendia os primeiros sete anos, a puerícia os segundos, a adolescência os terceiros e parte dos quartos, a juventude ia até aos 35 anos e os outros períodos sucediam-se ao ritmo dos septenários seguintes (Abreu, 1773, p. 437-438). A segunda metade do século, apesar do avanço da medicina, não conheceu grandes novidades no que diz respeito à problemática em causa. A posição de Manuel José Leitão (1788, p. 42-47) pode exemplificar exatamente isso, pois a sua classificação, ainda que formalmente apresente algumas variações, não deriva de uma compreensão substancialmente diferente do desenvolvimento do indivíduo. De fato, apesar de entender que a vida humana se desenrolava desde o momento da concepção até ao instante da morte, iniciou a contagem das diferentes "épocas" do "progresso da vida humana” somente a partir do nascimento para definir quatro idades, indo a primeira até aos catorze anos, mas subdividida em infância e em puerilidade; a segunda, tendo por limite superior os vinte e quatro anos, contemplava a adolescência, a virilidade ia até aos cinqüenta anos, quando começava a velhice, que abrangia três subperíodos - velhice fresca, velhice mediana e crepitude.

Não se torna necessária uma análise pormenorizada para se verificar que o decorrer do tempo não possibilitara resolver a existência de diferentes posições no que concerne às estratificações etárias e que elas, em alguns aspectos, ultrapassam a mera questão quantitativa. Por outro lado, as diferenças que encontramos nas classificações etárias demonstram que elas resultavam de um esforço de compreensão do desenvolvimento que tinha margem de manobra para uma criatividade especulativa. Todavia, não há dúvida de que os médicos de setecentos encontravam sentido nessas classificações, procurando fazer com que elas os orientassem em sua prática clínica. 
Vivendo nos séculos 18 e 19, Francisco de Melo Franco (1823, p. 10) foi dos que sublinhou a importância da consciencialização das idades pelo médico, porque sem essa compreensão atuaria ao acaso, "empregando quasi sempre sem acerto as suas diligencias, sem distinguir as molestias, que atacão particularmente certos orgãos segundo as diferentes idades". De acordo com esta perspectiva, a infância era encarada como o período durante o qual a cabeça recebia as preferências do crescimento. Segundo a argumentação de Melo Franco, isso fazia com que se acumulassem, por exemplo, "as forças necessarias para a dentição" e para a "formação dos cabellos", como também pela facilidade com que todas as doenças desse tempo implicavam com a cabeça e por "certas affecções, proprias deste orgão", somente se desenvolverem nesta idade, "como a crusta lactea, hydrocephalo, inchação das parotidas, purgação de ouvidos, de nariz, etc." Já na puberdade, a "tendência das forças e movimentos que a natureza dirigia para a cabeça no tempo da infância" voltava-se para o peito, provocando a mudança do tom da voz, o alargamento do tórax, o fortalecimento dos pulmões, do coração e das grandes artérias, mas também "as hemoptyses, as dores, as inflammações, e todas as molestias de peito", que neste período surgiam com maior freqüência (Franco, 1823, p. 8-9). Especial importância assumia, no entanto, o desenvolvimento dos órgãos sexuais, que, no entender de Melo Franco, não só modificava a configuração externa destes como também conferia "huma nova ordem de sentimentos, estabelecendo nelles o centro de irritabilidade, que se difunde por toda a organização".

Estes exemplos traduzem a preocupação em se encontrar o que caracterizava a especificidade de cada idade do ponto de vista do pensamento médico. É certo que a dificuldade em romper com as antigas classificações não deixava grande espaço de manobra para uma categorização mais específica dos diferentes momentos da infância, que chegava a incluir, muitas das vezes, até a puerícia. As idades eram, assim, categorias que pareciam favorecer uma atenção à especificidade infantil e, simultaneamente, prejudicar a emergência de uma compreensão que tivesse em consideração outras possibilidades de classificação. Recorde-se que não sendo as idades somente categorias de índole médica, o mais fácil seria seguir uma classificação consolidada e de aceitação generalizada, ainda que enriquecida com dados provenientes de um saber clínico mais ou menos empírico. Independentemente das conseqüências desta compreensão do desenvolvimento do indivíduo, importa sublinhar que, para além da relevância da sua aceitação generalizada, a sua persistência ao longo de décadas das centúrias de setecentos e de oitocentos confere-lhe, pelo menos, uma legitimidade de referencial analítico suportado pelo saber médico, acontecimento igualmente evidenciável em outros países.

Em meados do século 19, A. Becquerel (1864, p. 9), professor agregado da Faculdade de Medicina e médico do hospital de Paris, parece bastante consciente do sentido das idades e sente necessidade de pensar na sua reformulação. No capítulo II, "Des âges", da primeira parte de sua extensa obra, intitulada Traité elémentaire d'hygiene privée et publique, ${ }^{6}$ tem início com uma reflexão acerca da idade: "Nós atribuímos, em geral, o nome idades aos diversos períodos de desenvolvimento, de estado estacionário e de decréscimo, que se sucedem durante a evolução orgânica do homem desde seu nascimento até sua morte”. Ele acrescenta que toda divisão das idades é necessariamente artificial, na medida em que a evolução completa de um ser humano se faz sem transição, de uma maneira insensível, sem haver tempo de paradas/interrupções determinadas. Todavia, segundo ele, sempre se procura estabelecer para as idades uma divisão que relaciona épocas entre as quais haveria uma certa similitude, com base nas relações anatômicas e fisiológicas, e separar aquelas entre as quais existiria uma dessemelhança muito grande e muita marcada. A partir daí, refere-se a uma classificação antiga que admitia quatro idades (infância, adolescência, idade viril e velhice), a de Hallé e Daubeton, para, em seguida, apresentar aquela com a qual efetivamente opera.

Becquerel admite ser a divisão de Hallé$^{7}$ uma das primeiras "verdadeiramente científicas", a qual reparte a vida em cinco etapas, cabendo ainda subdivisões e variações, conforme o sexo. 
Quadro 1 - Idades da vida, segundo Hallé

\begin{tabular}{|c|c|c|}
\hline Terminologia & Descrição & Idades \\
\hline $1^{a}$ infância & & $\begin{array}{l}17 \text { anos } \\
-\end{array}$ \\
\hline $2^{a}$ infância - puerícia & $\begin{array}{l}\text { Meninos } \\
\text { Meninas }\end{array}$ & $\begin{array}{l}7-15 \text { anos } \\
7-13 \text { anos }\end{array}$ \\
\hline $\begin{array}{l}\text { Puberdade ou adolescência } \\
\text { (aptidão para reprodução) }\end{array}$ & $\begin{array}{l}\text { Homens } \\
\text { Mulheres }\end{array}$ & $\begin{array}{l}15-25 \text { anos } \\
13-21 \text { anos }\end{array}$ \\
\hline Virilidade & $\begin{array}{l}\text { Virilidade crescente } \\
\text { Virilidade confirmada } \\
\text { Virilidade decrescente }\end{array}$ & $\begin{array}{l}25-60 \text { anos } \\
21-50 \text { anos }\end{array}$ \\
\hline Velhice & $\begin{array}{l}1^{a} \text { fase - velhice } \\
2^{a} \text { fase - velhice avançada (época das enfermidades) } \\
3^{\text {a }} \text { fase - decrepitude (transição da vida à morte) }\end{array}$ & $60-70$ anos \\
\hline
\end{tabular}

A classificação de Daubeton, segundo o professor parisiense, desenvolve e regulariza a divisão antiga. Daubeton distribui a vida em seis fases: infância (do nascimento à puberdade), adolescência (até 20-25 anos), juventude (25-30/35 anos), idade viril (até 40-45 anos), idade de retorno (45-60/65 anos) e idade da velhice ou caducidade. Na seqüência, Becquerel apresenta a grade de idades com a qual trabalha, classificando a vida em sete etapas:

Quadro 2 - Idades da vida, segundo Becquerel

\begin{tabular}{|l|l|l|}
\multicolumn{1}{|c|}{ Fases } & \multicolumn{1}{c|}{ Terminologia } & \multicolumn{1}{c}{ Idades } \\
\hline $1^{\mathrm{a}}$ & Época do nascimento & Criança recém-nascida \\
\hline $2^{\mathrm{a}}$ & Primeira infância & Do nascimento até 2 anos \\
\hline $3^{\mathrm{a}}$ & Segunda infância & $2-12 / 15$ anos \\
\hline $4^{\mathrm{a}}$ & Adolescência & Idade da puberdade, de $12-15$ a $18-20$ anos \\
\hline $5^{\mathrm{a}}$ & Idade adulta & $20-60$ anos \\
\hline $6^{\mathrm{a}}$ & Velhice & 60 anos até morte \\
\hline $7^{\mathrm{a}}$ & Época da morte & Morte \\
\hline
\end{tabular}

No entanto, ciente da artificialidade da repartição, conclui essa primeira reflexão ${ }^{8}$ acerca das idades lembrando que as divisões são feitas apenas para facilitar o estudo e que não se deve atribuir mais importância do que elas merecem, dedicando cerca de 60 páginas para caracterizar cada uma das idades de sua cronologia, descrevendo e debatendo a situação de cada uma das etapas, ao mesmo tempo em que prescrevia as práticas adequadas para cada nível.

Esse debate aconteceu em diversas partes do mundo e principalmente no âmbito de escolas médicas, sendo apropriado pelos professores da Faculdade de Medicina do Rio de Janeiro (FMRJ) e futuros médicos dos trópicos, o que pode ser evidenciado em um conjunto de teses no qual o tema das idades comparece, entre elas, as oito que tratam diretamente da higiene da infância ou da primeira infância.

Com exceção da tese de $1840,{ }^{9}$ nas demais Becquerel é constituído em autoridade nas questões de higiene, sendo a reflexão acerca das idades um tema obrigatório em todas elas. A título de exemplo, na primeira tese que desenvolve o ponto referente à higiene da infância, seu autor, o Dr. Leitão (1840), inicia a dissertação debatendo o conceito de higiene, que para ele consiste em uma preocupação que remontava à antiguidade, em um meio voltado para "melhorar a sorte e adoçar a existência" dos semelhantes. Para ele, a higiene era um "interessante ramo da

\footnotetext{
Ao fim de cada seção, o autor apresenta uma bibliografia relativa ao assunto. Para o tema das idades, ele lista: GORDON (Bernard de), De conservatione vitae humanae, a die nativitatis usque ad ultiman horam mortis (vers. 1300). Lipsiae, 1570 , in-12. BUFFON, $D e$ l'homme, de l'enfance, de la puberté, de l'âge viril, de la viellesse et de la mort, in Oeuvres completes. HALLÉ, Encyclopédie. Méth., Art. Ages. T. I, p. 358. DAUBETON, Leçons professes aux Écoles Normales, t. VIII, p. 314. ESPARRON, Essai sur les âges de l'homme, thèse inaug. Paris, 1803, in $-8^{\circ}, \mathrm{n}^{\circ} 257$ DENDRIN, De l'influence des âges sur les maladies, these de concours. Paris, 1840. ESTÈVE, Considérations générales sur les âges étudiés, etc. Thèse inaug. Paris, 1859, in $-4^{\circ}, n^{\circ}$ 69.

${ }^{9}$ Isso pode ser atribuído ao fato de a $1^{\mathrm{a}}$ edição do livro do médico parisiense datar de 1851.
} 
nobre arte de curar", sendo, sem contradição, de "grande merecimento", nos dando a "maior das felicidades", fazendo-nos "gozar o melhor dos bens". Ainda nessa linha, assinala que a higiene é uma parte da "ciência médica assaz importante", sendo um ramo "da moral" e, segundo Rousseau, "uma virtude", acentuando que feliz era o povo que lhe prestava cultos e que cegamente obedecia a suas leis. Ao fim de seu prefácio
(Prefação), alerta que não era seu intento dissertar sobre a higiene em geral, nem o curto espaço de uma tese daria campo suficiente para o extenso desenvolvimento de que era suscetível semelhante objeto. Desse modo, procura precisar sua questão: "Nós nos limitamos somente a alguns dos pontos mais importantes relativos á primeira infância, ${ }^{10}$ que, como Mr. Hallé, consideramos d'esde o nascimento até a segunda dentição.”

Quadro 3 - Teses da FMRJ que desenvolvem o ponto Higiene da Infância

\begin{tabular}{|l|l|c|}
\hline \multicolumn{1}{c|}{ Tese } & \multicolumn{1}{c}{ Autor } & Ano \\
\hline Higiene da infância & Antonio Gonsalves d'Araujo Leitão & 1840 \\
\hline Higiene da primeira infância & José Marciano da Silva Pontes & 1863 \\
\hline $\begin{array}{l}\text { Higiene da criança do nascimento à queda } \\
\text { do cordão umbilical }\end{array}$ & Francisco Basilio Duque & 1864 \\
\hline Higiene da primeira infância & Ildefonso Archer de Castilho & 1882 \\
\hline Higiene da primeira infância & Nicolao Barbosa da Gama Cerqueira & 1882 \\
\hline Higiene da primeira infância & José Vieira Martins & 1882 \\
\hline Higiene da primeira infância & Severiano Martins de Oliveira Urculu & 1882 \\
\hline Higiene da primeira infância & José Cypriano Nunes Vieira & 1882 \\
\hline
\end{tabular}

A explicitação sobre a delimitação objeto da tese pelo clínico brasileiro é bastante interessante, porque nos põe diante da aceitação de uma classificação das idades da vida já clássica, que admitia a infância subdividida em duas, sendo a primeira a infância propriamente dita e a segunda a puerícia. Além disso, a explicitação era, na altura, também pertinente, porque indicava claramente o período abrangido, desfazendo o equívoco do título, Higiene da infância, que podia contemplar mais cinco ou sete anos pela classificação antiga, mais consensualizada, ou mais seis ou oito, caso fosse seguida a proposta por Hallé, pela qual António d'Araújo Leitão manifesta preferência.

Como vimos nos quadros apresentados, a primeira infância para Hallé não difere do intervalo normalmente considerado por outros domínios do saber e até por outros médicos da sua época e de várias décadas posteriores, mas Becquerel, em meados do século 19, entende que a primeira infância devia abarcar somente os dois primeiros anos, deixando os seguintes para a segunda infância. Esta divergência sobre a definição da primeira infância foi bem salientada por Luc (1998), que, compulsando 277 obras produzidas por 93 autores entre a metade do século 18 e o fim do 19, reconhece que os homens da ciência tomavam evidências distintas na tentativa de repartir a vida em idades mais ou menos homogêneas e que a primeira infância podia assumir mais ou menos três anos de diferença. Ora, independentemente dos argumentos utilizados ou da autoridade convocada, a idéia duma fase delimitada pelo desmame denominada de primeira infância encontra crescente aceitação na segunda metade de oitocentos.

Em Portugal, várias teses da Escola Médico-Cirúrgica do Porto, embora não se reconhecendo como seguidoras de Becquerel, parecem partilhar a idéia de uma primeira infância associada aos primeiros anos de vida da criança. É o caso, por exemplo, da "dissertação inaugural" apresentada, em 1890, por Júlio Maximo do Nascimento Trigo, intitulada Algumas palavras sobre a alimentação da primeira infancia, na qual se faz depender a saúde ao longo da vida do "modo como se trata das creanças nos dois primeiros annos" (prefácio), ou da apresentada por Alvaro 
Martins, em 1898, com o expressivo título Hygiene e educação psychica nos três primeiros annos da vida, ou ainda da de António Augusto Proença, que se intitulava Algumas palavras sobre a hygiene da primeira infancia e que termina exatamente com uma pequena abordagem sobre o desmame. Contudo, a mais interessante das dissertações relativas à primeira infância foi redigida por Aurélia de Moraes Sarmento, no ano de 1891. Nesse seu trabalho, simplesmente denominado Hygiene da primeira infancia, a autora manifesta claro propósito de se confinar a este período, mas sabe que está perante um "limite artificial" porque "o trabalho de desenvolvimento organico na creança se opera insensivelmente e sem transição acentuada" (introdução). Embora admita, por isso, que, anatomicamente, se possa demarcar a primeira infância pela queda da primeira dentição, considerando "a questão pelo lado hygienico" entende que o limite se deve situar no fim da lactação. Em coerência com a sua posição, seu trabalho termina com um capítulo sobre o desmame, onde, no entanto, se recusa a "estabelecer um limite fixo com relação à época em que as creanças devem ser desmamadas" (p. 77).

A consolidação de uma primeira infância vinha na seqüência de uma longa preocupação com as crianças menores e traduzia um reconhecimento de uma especificidade que a estatística ajudava a confirmar. Em uma das dissertações apresentadas à Escola Médico-Cirúrgica do Porto, em finais de oitocentos, Francisco da Silva Carvalho dava conta de que o aumento da mortalidade na cidade de Lisboa não se distribuía igualmente por todas as idades, para explicitar que na "primeira infância, de 0 a 2 annos, é que se deu o grande augmento da lethalidade" (Carvalho, 1894, p. 24). Em outro trabalho do mesmo gênero, apresentado na mesma instituição, quatro anos depois, José Joaquim Vieira Filho escrevia que "a enorme mortalidade das creancinhas nos primeiros annos de vida" era devida, em grande parte, à "ignorancia das regras mais rudimentares da hygiene alimentar infantil" (Vieira Filho, 1898, p. 71). Esta era, por certo, a razão de terem sido apresentadas à referida escola médica um interessante número de dissertações sobre a alimentação até aos dois anos, o que reforça a idéia de que o saber médico atribuía especial importância a esta fase da vida. Embora a alimentação concentrasse grande atenção e contribuísse para a particularização da primeira infância, a higiene devia atuar sobre todos os aspectos que implicassem o desenvolvimento da criança. A idéia era atuar preventivamente sobre o seu bem-estar presente e futuro. Mas a higiene da infância não deixava também de ser pensada em função do adulto. Alguns nela pensavam como condição de uma virtual felicidade. Entre eles estava certamente o aluno da FMRJ, António d'Araújo Leitão, que escrevia na sua tese: "A Hygiene d'esta época da nossa vida merece muita consideração; porquanto he ella, que vai plantar os alicerces de huma existência feliz, he ella que fará gozar hum lisongeiro porvir."

Nessa linha de raciocínio, a existência feliz e o lisonjeiro porvir conjuntamente com a regeneração da raça funcionam como eixos de uma argumentação que pressupõe a necessidade da intervenção da racionalidade médica sobre a "flor da infância”, de modo a construir um discurso especializado a respeito desse período, capaz de prescrever as regras para assegurar a continuidade da vida, afastando as crianças das práticas e sujeitos convertidos, na lógica da ciência, em ignorantes, curiosos e indiscretos. Esse movimento da racionalidade médica, procurando instituir as verdades da ciência ou da razão a partir da lógica da natureza, encontra-se, no entanto, com realidades sociais e culturais que obrigam a olhar em diversas direções. Nesse sentido, no discurso sobre a infância, torna-se perceptível a preocupação com as crianças submetidas a condições desiguais. No caso dos discursos autorizados pelas escolas médicas aqui referidas, isso pode ser evidenciado no conjunto das teses já apontadas, como também nas que se debruçam sobre instituições destinadas às crianças. Em uma das que foi apresentada, em 1878, à Escola Médico-Cirúrgica do Porto, dizia-se num tom bastante otimista:

Hoje a sociedade tem asylos para a creança a quem a família não póde alimentar e educar, abre-lhe as escólas primarias onde a sua debil inteligencia começa a ensaiar os primeiros passos, e mais tarde, quando esta, já um pouco robustecida, se sente capaz de estender o vôo por mais largos horizontes, não lhe são vedados os templos onde as sciencias e as artes estabeleceram sua morada (Lima, 1878, p. 18). 
Nestas linhas, o futuro médico revelava-se contaminado pelo desenvolvimentismo e pelo positivismo que o faziam crente de estar num processo inabalável de progresso científico e social. Ele acreditava que a sociedade do seu tempo era melhor que a de tempos passados, mas que a tendência era para que viesse a ser ainda melhor. Por isso mesmo, o seu otimismo assentava menos no estado em que se encontravam as instituições do que no que projetava para o futuro. Era com convicção que escrevia:

Com certeza que o asylo, a escóla, o hospital, os variados hospícios que possuímos hoje distam bastante da perfeição que podem e devem atingir, pela qual nós todos almejamos, e que de certo em um futuro mais ou menos proximo veremos realisada, porque não são poucos os lidadores que para tarefa tão ardua fazem converir as suas forças (Lima, 1878, p. 18).

Vendo bem, só uma perspectiva de evolução progressiva da sociedade podia favorecer uma apreciação tão benévola e esperançosa sobre o conjunto das instituições destinadas às crianças. No ano seguinte, uma outra dissertação descrevia o estado da generalidade das escolas em Portugal como casas sem ar, sem luz, humidas e frias, casas nada adequadas ao fim a que se destinavam (Cruz, 1879, p. 99). Em 1890, Pedro d'Almeida d'Eça, que dissertava sobre Hospitaes de creanças, seguia a transcrição de Haussonville para concordar que se o hospital era um lugar tão “infecto e pouco sadio” (D’Eça, 1890, p. 36), mas que casa paterna da gente pobre não era melhor. Mas se havia hospitais a funcionar em péssimas condições, também havia casos que mereciam uma apreciação positiva (Carvalho, 1894). De qualquer modo, os hospitais para crianças estavam destinados a receber uma população marcada pela pobreza, idêntica à que passava pelos dispensários, pelos hospícios, pelos asilos. Ora, esta era a população infantil pobre que acabava por estar mais sujeita à lógica médico-higiênica, designadamente da que derivava da definição de diferentes etapas da vida. Por exemplo: o Hospital Maria Pia, do Porto, recebia crianças desmamadas até aos 12 anos, idade a partir da qual se era admitido no hospital da Misericórdia; a Casa-hospício do Porto recebia crianças expostas, abandonadas ou desvalidas até aos sete anos de idade, e a partir desta idade elas eram remetidas para o asilo-escola (Carvalho, 1894). Neste caso estava-se a cumprir uma determinação legislativa, mas esta era, de fato, a idade mais consensual para se iniciar a escolarização.

\section{As idades da vida e instituições para a infância}

A situação das crianças estava longe de se apresentar idêntica para todas, mas muitas eram as que estavam destinadas a uma vivência institucionalizada em regime de internato. Riant, autor de livros versando a relação entre higiene e educação, com repercussão em Portugal e no Brasil, teve essa realidade em atenção e apresentou a sua reflexão em um de seus tratados especialmente dedicado a esse objeto, ${ }^{11}$ considerando diferentes tipos de instituições. Na sua ótica, no entanto, a entrada no internato implicava uma separação que, no caso da França, podia ter início, em muitos casos, já no período do aleitamento, porque, como testemunhava, era aí, sobretudo, que as mães não hesitavam "em confiar a outras mulheres, a mercenárias, a tarefa de cuidar e de alimentar seus filhos que tanto amam". ${ }^{12}$ Mesmo independentemente disso, havia que reconhecer a existência de internatos variados, havendo aqueles que recebiam crianças muito pequenas. Considerando estes casos, o higienista entende que as instituições deveriam ter uma divisão especial de modo a afastar o mais possível os "minimes", dos "petits", "moyens" e "grands", posto que a divisão inferior, dos "minimes", era, segundo ele, e isso não poderia ser esquecido, um viveiro de doenças eruptivas e, por conseguinte, uma vizinhança perigosa para os outros alunos e um terreno sempre pronto a receber e a desenvolver todos os germes. Deste modo, ancorado no saber médico-higiênico, encena-se a produção de uma instituição na qual a promiscuidade das idades deveria ser evitada, configurando os contornos do que vai ser afirmado como modelo educativo ideal: as classes de idade, fundamento para uma homogeneidade pretendida. Daí a necessidade de local, horário, exercícios, hábitos, regime e pessoal à parte. Em função disto, defende os internatos no campo como os mais recomendados para os 
“jeunes enfants" porque contrastariam com os existentes nas grandes cidades, caracterizados pela má qualidade do ar, pelos corredores estreitos, altas muros, ausência de verde e alegria dos estabelecimentos. Para ele, a divisão dos "mais pequenos" teria necessariamente as características de um infantário, sendo necessários cuidados especiais, correspondentes aos dispensados pela mãe. Nesse caso, a intervenção do educador deveria ser "rara e sóbria". As crianças pequenas necessitavam de numerosas recreações, estudos muito curtos, alimentação equilibrada, apropriada, e de uma vigilância feita por um pessoal devotado, que, em sua ótica, deveria ser feita por freiras, habituadas a esse serviço e que a ele se dedicavam de modo geralmente admirável.

O programa higienista aqui exposto é ajustado ao modelo da instituição total, ${ }^{13}$ valendo chamar a atenção para a ênfase na dimensão dos cuidados com a "mais tenra idade", que não exigiria uma profissionalização para lidar com essa "etapa” da vida, sendo suficiente a dedicação. Do mesmo modo, cabe sublinhar a força da instituição na construção do que seria específico para as diferentes idades da vida. Este aspecto reaparece também quando Riant aborda a higiene do trabalho intelectual, chamando a atenção para uma espécie de ajuste entre procedimentos escolares e a idade dos alunos, e volta a ser retomada no debate relativo à higiene moral, especialmente quando o autor discute as condições necessárias para gerar uma "feliz aliança entre disciplina e liberdade”, considerando uma dessas condições precisamente a idade dos alunos. ${ }^{14}$ No que se refere à idade de admissão dos internatos, o higienista defende que, salvo casos excepcionais, ela não deveria ser inferior a 7-10 anos, visto que a presença dessas crianças perturbaria as regras, a disciplina, e representaria um perigo para a saúde dos outros alunos; mas, por outro lado, também entende que seria perigosa a admissão de alunos de mais idade, porque tenderiam a se mostrar rebeldes à disciplina dos internatos.

Ao mesmo tempo em que advogava uma idade ideal para a admissão nos internatos, Riant defende a necessidade de uma vivência no ambiente da família, distinguindo, assim, uma idade da casa e uma idade da escola. Com isso, critica as famílias que desejam esse tipo de separação precoce, afirmando não haver qualquer benefício fosse do ponto de vista intelectual, físico e moral:

A bien examiner le resultat pour lequel les internats accepteraient une lourde responsabilité, les familles um inutile et immoral sacrifice, il faut conclure ainsi:

Laissons ces jeune enfants au foyer domestique, à moins des raisons graves, jusqu'a l'heure où la necessite d'un travail séerieux et profitable pourra justifier leur entrée dans l'internat. Jusque là, le meilleur des maîtres, c'est la mère. (Riant, 1877, p. 329)

Para Riant, a higiene e a moral estavam de acordo em solicitar às famílias que não enviassem crianças muito pequenas para um internato, porque tal podia comprometer a sua saúde, suas forças ou as disposições da inteligência, deixando vazia a "primeira página" que deveria ser reservada à lembrança dos pais, seus primeiros mestres. Para o médico parisiense, a admissão de um aluno em um internato não constituía uma simples e breve formalidade. Não se tratava apenas de acertar preço e condições materiais. No dia em que o aluno efetivamente entrava no internato, significava que passava a existir uma criança a menos no seio de uma família e uma a mais no interior de um estabelecimento de instrução.

Esta admissão no internato significava toda uma vida diferente e pressupunha uma atitude educativa mais racional. $\mathrm{O}$ médico defende mesmo uma anamnese profunda da família, como estratégia para se conhecer melhor o aluno e, assim, se poder orientar com mais eficácia a ação dos mestres, ciente do lado frágil, dos pontos delicados e das debilidades anteriores do aluno e da família. Entendia também o clínico francês que a higiene moral exigia a separação dos alunos de idades diferentes, devendo cada idade ter um espaço próprio para estudar, dormir, vestir, alimentar, ter aulas, passear, rezar... O internato era, portanto, uma instituição vocacionada para uma ampla idade escolar, ${ }^{15}$ mas que se devia organizar em função da diversidade etária dos alunos que acolhia.

Como bem assinala Becchi, ao analisar a infância no século 19, crianças de todas as idades estão presentes na cena social, e, por toda a Europa, um poderoso
${ }^{13}$ A esse respeito, cf. Goffman (1999) e Joseph (2000).

${ }^{14}$ As outras são: as relações dos alunos entre si, com os mestres, com os inspetores, com as outras pessoas, de fora e de dentro do internato, o sistema de recompensas e punições adotado e ter em grande conta o ensino in telectual, moral e religioso dado aos alunos.

${ }^{15}$ A respeito da produção da idade escolar, cf. o artigo de Gouvêa, 2004. 
discurso sobre a infância acompanha esse fenômeno, reconhecendo a necessidade de se programar a passagem do estado da natureza (a infância) ao estado social (o adulto), da vida selvagem à vida civilizada. Esses desafios são objeto de tratados na filosofia e na ciência, como o de Rousseau, Itard e Fourier, para trazer apenas três exemplos indicados por Becchi.

A presença da infância na cena social também vai ter uma visibilidade nos debates relativos aos espaços específicos da criança, na casa, na rua, no trabalho e na escola - reflete-se, por exemplo, sobre lugares para brincar, para assistir a espetáculos e para se exercitar - , debates que também têm desdobramento diferenciado no espaço privado, na medida em que, nas camadas médias e superiores, há uma tendência a separar uma peça da casa para as crianças, que, progressivamente, vão sendo ensinadas a circular por outros espaços, integrando-se paulatinamente à vida dos adultos. No caso das crianças pobres, elas possuem outros lugares, outra iniciação ao mundo adulto, são submetidos a um outro tipo de vigilância. O resultado é que se tornam grandes mais cedo; sua infância é encurtada inclusive em sua dimensão material, e a pedagogia que resulta dessa organização do espaço é diferente: a aprendizagem dos costumes do mundo adulto é mais rápida, e, sobretudo, o apelo ao uso do corpo é bem mais evidente. A promiscuidade das idades ensina experiências práticas, afetivas e sexuais omitidas das crianças das classes superiores.

Essa entrada da criança na cena social também vai implicar a recomendação de jogos e materiais lúdicos dotados de valor moral e socializante. De acordo com Becchi, o impacto desta pedagogia dos jogos é tão grande que, na Alemanha, Inglaterra e na própria França, a produção em série desses materiais vai superar a produção artesanal. Os jogos vão sendo diversificados, aperfeiçoados, adaptando-se cada vez mais à idade e ao sexo. "Cada idade tem seu equipamento, cada vez mais preciso em seu objetivo de aprendizagem de comportamentos, de hábitos, de papéis sociais, até chegar ao estágio/estádio do jogo científico.” (1998, p. 171, v. II). A diferenciação dos sexos e das idades também virá pela vestimenta adotada. A diferenciação também está associada aos livros sobre as crianças e aos destinados à criança, mas é a escola que se torna o principal lugar de aculturação da infância. Aí também já se marca uma escola maternal (antes dos 6 anos) e uma escola elementar (a partir dos 6/7), cuja distinção também é evidenciável na própria arquitetura dos prédios escolares, repartição que colabora para fortalecer a tese das etapas da vida e da especificidade de cada uma.

A condição social e, particularmente, o mundo do trabalho vão trazer evidências do arbitrário dessa repartição, na medida em que muitas crianças trabalham nas fábricas, nas minas, no campo e mesmo no espaço da casa. Com o avanço do discurso em favor da especificidade da infância e seu rebatimento na esfera da legislação é que o trabalho infantil vai paulatinamente sendo caracterizado como pernicioso, já que impediria o pleno desenvolvimento das potencialidades humanas. Chassagne (1998) demonstra que o longo processo de regulamentação do trabalho infantil ocorrido na Europa é resultante do esforço de se fazer admitir o direito de intervenção do Estado no que se refere ao trabalho infantil. Tal direito foi fortemente apoiado pelos discursos de moralistas, pedagogos, higienistas, cientistas e filantropos que, no limite, procuravam estancar problemas demográficos (como a alta mortalidade infantil) e o da degeneração. Nesse sentido, defendiam que as novas gerações deveriam ser bem educadas, e isso implicava respeitar o ritmo da natureza esperando pelo tempo adequado a determinadas aprendizagens, o que o trabalho infantil contrariava. Com a determinação da escolaridade obrigatória, que se generalizou no século 19, de algum modo se respondia a essa preocupação, pois, quando cumprida a legislação, atirava-se para mais tarde a entrada das crianças no mundo do trabalho. Mesmo assim, a legislação de importantes países europeus mostrava-se bastante tímida na proteção da infância, pois admitia, em geral, que crianças como menos de 10 anos pudessem trabalhar em fábricas (Lima, 1880).

A situação sanitária e educacional da criança de oitocentos dificilmente correspondia às prescrições dos higienistas, pedagogos e moralistas desse século. Todavia, ela também não era imune aos discursos e às iniciativas provenientes de pessoas culturalmente prestigiadas e, por vezes, socialmente influentes. Estas, partindo de motivações e saberes diversos, 
mas dotados de cultura e de capacidade de comunicação, faziam-se ouvir junto de quem podia promover as medidas adequadas e iam conseguindo que os cuidados para com a infância tivessem mais impacto. Claro que, para isso, muito contribuiu o esforço de homens e mulheres da ciência e das letras para decifrar a infância, descrevendo suas características, sua natureza, sua evolução, diferenciando períodos a partir de aspectos tidos por relevantes. Esta preocupação de olhar especificidades do desenvolvimento e de lhes dar resposta levando em consideração a diversidade das condições sociais em que se inseriam as crianças terminou por criar condições para se definir instituições, materiais e práticas específicas para cada fase da vida, como bem assinala o estudo de Luc (1998). Havia, assim, bastante consenso sobre a idade de ingresso na escola elementar, o que se traduzia até nas disposições legislativas de diversos países. No entanto, na Inglaterra, Itália, Alemanha e França há um impulso na construção de escolas de "jeunes enfants" voltadas para o atendimento de crianças de 3 a 6 anos, para cuja criação foi importante uma sensibilidade higiênico-pedagógica que contou com a participação dos médicos, intervindo no funcionamento dessas escolas, examinando seus usuários, redigindo manuais de higiene e conseguindo, por meio das suas esposas, algumas inspetoras benévolas.

Como já vimos, esta fase não era contemplada na tradicional classificação das idades. Os médicos tardaram também a prestar-lhe atenção especial. No entanto, a transformação demográfica das crianças que já não estavam sob a proteção de uma ama, mas que também não eram consideradas capazes de freqüência escolar, chamava a atenção das pessoas mais sensíveis ao filantropismo e às disposições do higienismo. Assim, preocupadas com a manutenção da vida e produção de uma geração sadia, desenvolveu-se um movimento em muitos países da Europa sobre a necessidade de se tratar esta fase em sua suposta particularidade, como acentua Luc (1998, p. 338):

En réclamant une éducation globale de trois-six ans par une pédagogie inhabituelle - du mouvement, de l'affection et de l'intuiton, les pionniers de l'école enfantine l'opposent à tous les lieux d'accueil traditionnels des bambins: la nourrice, la garderie ou l'hospice, qui dispensent sourtout des soins physiques en mélangeant les ages; l'école, qui associe l'enseignement abstrait à l'immobilité; l'atelier, qui pertube la croissance en exigeant des efforts prématurés. La formule d'une école spéciale prouve une conscience relative des particularités du jeune enfant, distingué des nourrissons sans être pour autant assimile aux sujets capable de rasionner.

Sublinhe-se, no entanto, que a transcrição nos remete à existência de uma situação educacional que já antecipa o movimento pedagógico consagrado pelos jardins de infância. De fato, as crianças pobres desta idade encontravam nos asilos e instituições congêneres o espaço a elas especialmente destinado, enquanto para as crianças da primeira infância estavam destinadas as creches. Estas instituições, contudo, tinham como preocupação fundamental a preservação da condição física das crianças que acolhiam e, por isso, tendiam a se organizar na base dos princípios da caridade cristã e dos preceitos higiênicos mais insistentemente advogados pelos médicos da época. Ao longo do século 19 se desenvolve um movimento pedagógico que procura fomentar instituições com preocupações educacionais mais amplas, onde já estavam bastante claras as vertentes do desenvolvimento sensorial, intelectual e social. Assim, antes do aparecimento e legitimidade da psicologia infantil, razão que vai disputar a capacidade e legitimidade de decifrar a alma da criança pequena, a escola infantil e o olhar pedagógico profissional partilhado por diferentes sujeitos contribuíram para demonstrar a especificidade dessa idade da vida.

\section{Considerações finais}

Olhando para as últimas décadas do século 19, vemos já um dispositivo institucional e uma lógica legitimadora que são simultaneamente resultado e fator de reforço de uma racionalidade que encara a infância como uma idade particular sujeita a períodos de crescimento ou desenvolvimento. Sem querermos aqui refletir sobre o tão polêmico sentimento de infância, admitimos que as crianças de tempos diferentes da história estiveram 
sujeitas a compreensões específicas sobre o que representavam e as formas de controle e aprendizagem que derivavam da tecnologia pedagógica então disponível. Nesse sentido, compreende-se que não se pode esperar o mesmo tipo de abordagem em relação às crianças de períodos social e culturalmente diversos. Até a Idade Moderna dificilmente seria concebível a infância associada a uma idade eminentemente escolar e marcada fundamentalmente pelo discurso médico, o que já se tornou uma evidência bastante forte em parte significativa da Europa oitocentista. Todavia, os séculos anteriores foram, sobretudo, condicionados culturalmente pela Igreja, e não se deve ignorar que ela incorporou saberes legados pela Antigüidade e os adaptou, tendo em vista a regulação da vida dos cristãos. Por essa razão, não se estranha que as idades da vida já definidas e consideradas por gregos e romanos tenham servido de referência para determinar períodos de diferentes responsabilidades e dignidade. De qualquer modo, não há dúvida de que a partir do advento da modernidade foram geradas dinâmicas sociais e culturais obviamente assentes em modificações econômicas e no emprego de novas tecnologias, que propiciaram crescente interesse pela educação e um investimento médico cada vez maior sobre a preservação da saúde da criança. A confluência destas condições levou a que se elaborasse uma racionalidade que, sem perder de vista um percurso traduzido pelas idades da vida, se deteve especialmente no período do crescimento para delimitar fases que dessem sentido a intervenções mais específicas e eficazes.

Pensar a infância passou, pois, a implicar trabalhar com a idéia de uma vida segmentada, impondo o reconhecimento de marcos que tornassem possível identificar o começo e o término de diferentes fases, constituindo, assim, um verdadeiro gradiente das idades, evolutivo e linear, procedimento este que, pela busca do que é semelhante em cada etapa, ao repartir a vida de modo mais detalhado do que a clássica idéia de ciclo, expresso no fluxo inevitável do nascimento-crescimento-reprodução-morte, concorre para unificar o que se encontra recoberto em cada uma das idades da vida. Esta unificação, no entanto, não corresponde às experiências culturais pelas quais passa cada sujeito em diferentes momentos da vida. Com os mesmos 7 anos há, por exemplo, crianças na rua, sem teto, prostituídas, crianças abrigadas em instituições de caridade, crianças em lares sem pai, sem mãe, sem família nuclear, sem cuidados, crianças trabalhadoras submetidas às mais variadas formas de violência e de privação e, por outro lado, crianças bem alimentadas, bem vestidas, protegidas e recobertas de atenção, crianças consumidoras exigentes e integrantes de um sistema de serviços de saúde, educação e lazer. Unificação que pode ser percebida nos manuais e guias de higiene do século 19, ainda que nem todos produzam esse efeito, mas que não se ficou por aí. Uma rápida passagem de olhos por revistas, programas de tv, vídeos, filmes, propagandas, músicas, peças de teatro, páginas da Internet, brinquedos, jogos, livros de literatura infantil e salas de aula, por exemplo, colocam-nos perante uma infância que evolui homo-geneamente, porque sujeita a uma mesma cronologia. Claro que a organização destes produtos se insere numa representação dominante e universalizante de infância e, por isso, também acabam por contribuir para o modo como se tende a conceber os sujeitos da mais tenra idade.

De qualquer modo, é preciso reconhecer que isto é resultado de um amplo e generoso movimento que pretendeu compreender a infância a partir das suas especificidades. De fato, a cronologia da vida recebida da antigüidade, marcada por meras transformações anátomo-fisiológicas ou por indicadores de desempenho intelectual freqüentemente associados a uma interpretação unitária do mundo, cedeu perante uma racionalidade mais sofisticada derivada de uma maior atenção para com as crianças, e isso foi fundamental para uma organização dos cuidados de saúde e de educação que tem marcado a qualidade de vida da população contemporânea que a ela tem estado sujeita. Como freqüentemente acontece, idéias generosas e saberes razoavelmente fundamentados acabam deturpados por dogmatismo ou rotina. Também neste caso, assim sucedeu e por isso se viu e vê forçar a natureza para se cumprir a ditadura da cronologia. Diante disto, compreende-se o aparecimento de posições radicais, como a de Barrie - só que as crianças devem crescer, e elas parecem gostar de crescer. Nesse sentido, importa, por um lado, compreender como o crescimento foi percebido e organizado e em que 
medida a definição de idades traduz essa compreensão e, por outro lado, situar a proveniência, o alcance e a tendência das posições sobre os aspectos postos em discussão. Este texto pretende exatamente se inserir nesse esforço, que a História da Infância deve perseguir, de esclarecer sobre a pertinência das racionalidades vigentes sobre o desenvolvimento infantil e em que medida elas se constituem protagonistas de novas orientações de assistência ou de educação ou refletem modelos institucionalizados delineados em função de interesses de poderes dominantes. Estando nessa terra dos homens, importa não ignorar os interesses que os mobilizam e o modo como dispõem, através de diferentes instituições (médicas, jurídicas, religiosas, escolares), normas que balizam o percurso das pessoas, pois crescer não significa passar pela experiência delineada por uma mesma e única perspectiva de infância.

\section{Referências bibliográficas}

ABREU, José Rodrigues de. Historiologia medica. Tomo primeiro. Lisboa Occidental, 1773.

ABREU, Márcia. O leitor e a história literária. 2002. Disponível em: <www.pucrs.br/ fale/pos/historiadaliteratura/gt/\#2 > . Acesso em: março de 2003.

ARIÉS, Philippe. História social da criança e da família. Rio de Janeiro: Guanabara, 1981.

BARRIE, James Matthew. Peter Pan. 1904. Disponível em: < http://www.jmbarrie.co.uk/ jb_index.html >. Acesso em: 2 de agosto de 2005.

BECCHI, Egle. Le XIX siècle. In: BECCHI, Egle; JULIA, Dominique. Histoire de l'enfance en Occident - du XVIII siècle à nos jours, vol. II. Paris: Seuil, 1998.

BECCHI, Egle; JULIA, Dominique. Histoire de l'enfance, histoire sans paroles? In: HISTOIRE de l'enfance en Occident - de l'antiquité au XVII siècle, vol. I. Paris: Seuil, 1998.

BECQUEREL, A. Traité elementaire d'hygiene privée et publique. 3. ed. (com adição e bibliografia feita por Beuagrand). Paris: P. Asselin, 1864.

CARVALHO, Francisco da Silva. A mortalidade das creanças e a assistencia publica. Porto: Typographia de Cristovão A. Rodrigues, 1894.

CASTRO, Luiz de Barros de Faria e. Breves considerações sobre a alimentação da primeira infância. Porto: Typographia de Viúva Gandra, 1888.

CHASSAGNE, Serge. Le travail des enfants aux XVII e XIX siècles. In BECCHI, Egle; JULIA, Dominique. Histoire de l'enfance en Occident - du XVIII siècle à nos jours, vol. II. Paris: Seuil, 1998.

CHAUVIN, Daniele (Org.). L'imaginaire des âges de la vie. Grenoble: ELLUG, 1996.

CHAVES, Armando. Creanças, educação e hygiene. Porto: Typographia A. F. Vasconcellos, suc., 1902.

COMÉNIO, João Amós. Pampaedia (Educação Universal). Coimbra: Faculdade de Letras da Universidadede Coimbra, 1971.

COMÉNIO, João Amós. Didáctica Magna. Tratado da arte universal de ensinar tudo a todos. 3. ed. Lisboa: Fundação Calouste Gulbenkian, 1985. 
CRUZ, Emygio Pereira. Hygiene das escólas. Porto: Typographia Occidental, 1879.

D`EÇA, Pedro d’Almeida. Hospitais de crianças. Porto: Typographia Occidental, 1890.

DEVAY, Francis. Traité spécial d'hygiène des familles. Paris: Labé - Librarie de la Faculté de Médicine, 1858.

FELGUEIRAS, Nicolau Maximo. Apontamentos sobre educação physica. Porto: Typographia Occidental, 1882.

FÉNELON, François de Salignac de la Mothe. Da educação das meninas. Paris: Typographia de Fillet Fils Ainé, 1852.

De l'éducations des filles. Première version. In: LE BRUN, Jacques. Fénelon Oeuvres. Paris: Gallimard, 1983.

FERREIRA, António Gomes. A criança no conhecimento médico de seiscentos. Revista Portuguesa de Pedagogia, ano XXIII, 1989. Editora, 2000.

Gerar, Criar, Educar. A criança no Portugal do Antigo Regime. Coimbra: Quarteto FERREIRA, António Gomes; PEREIRA, Ana Maria Patrício. Um relance sobre a criança do século XVI. Revista Portuguesa de Pedagogía, ano XXI, p. 169-198, 1987.

FRANCO, Francisco de Melo. Elementos de hygiene: ou dictames theoreticos e practicos para conservar a saude e prolongar a vida. Lisboa, 1823.

GOFFMAN, Erving. Manicômios, prisões e conventos. São Paulo: Perspectiva, 1999.

GONDRA, José G. Artes de civilizar - medicina, higiene e educação escolar na Corte Imperial. Rio de Janeiro: Eduerj, 2004.

GOUVÊA, Maria C. S. Tempos de aprender - a produção histórica da idade escolar. Revista Brasileira de História da Educação, Campinas, 2004.

GUIZOT, Mémoires pour servir à l'histoire de mon temps. Apud RIANT. L'higiène et l'éducation dans les internats. Paris: Hachette \& cia, 1877. Disponível em: $<$ www.jmbarrie.co.uk> e <www.kirjasto.sci.fi/jmbarrie.htm>. Acesso em: 31 de agosto de 2005. p. 171

JOSEPH, Isaac. Erving Goffman e a microssociologia. Rio de Janeiro: FGV, 2000.

KATZ, Chaim; FREIRE, Jurandir. O colapso da infância. Folha de S. Paulo, 3 de julho de 2005. Caderno Mais.

LE BRUN, Jacques. Fénelon - Oeuvres. Paris: Gallimard, 1983.

LEITÃO, Manuel José. Tratado completo de anatomia e cirurgia com hum resumo da história da anatomia e cirtugia, seus progressos e estado della em Portugal. Lisboa, 1788. 4 Tomos.

LEVI; SCHMITT. Histoire des jeunes em Occident, 2 vol. Paris: Seuil, 1996.

LIMA, Antonio Martins de Souza. A hygiene e o trabalho das creanças. Porto: Imprensa Commercial, 1880.

LIMA, Manoel Carvalho d'Araujo. Creches. Porto: Typographia Oriental, 1878. 
LOBO, Alfredo Duarte. A saude da infancia ou conselhos ás mães sobre a conservação dos filhos durante os ultimos tempos da prenhez e sua educação physica no primeiro período da vida commum. Porto: Typographia de José Pereira da Silva \& Fº 1865.

LUC, Jean-Noël. Les premières écoles enfantines et l'invention du jeune enfant. In: BECCHI, Egle; JULIA, Dominique. Histoire de l'enfance en Occident - du XVIII siècle à nos jours, vol. II. Paris: Seuil, 1998.

MARANO, Hara Estroff. De olhos bem fechados. Folha de S. Paulo, 20 de fevereiro de 2005. Caderno Mais.

MARTINS, Álvaro. A higiene e a educação psíquicas nos três primeiros anos de vida. Porto: Papelaria e Typographia Academica, 1898.

PIMENTEL, António Venâncio da Gama. Algumas considerações sobre a amamentação. Porto: Imprensa Moderna, 1892.

PROENÇA, António Augusto. Algumas palavras sobre a hygiene da primeira infância. Porto: Typographia de A. F. Vascondellos, succ., 1901.

RIANT, A. (1877) L'higiène et l'éducation dans les internats. Paris: Hachette \& cia. Disponível em: < www.jmbarrie.co.uk> e < www.kirjasto.sci.fi/jmbarrie.htm>. Acesso em: 31 de agosto de 2005.

RIBEIRO, Guilherme Urbano da Costa. A mortalidade infantil no Porto. Porto: Typ. A vapor da real officina de S. José, 1902.

SARMENTO, Aurélia de Moraes. Hygiene da primeira infância. Porto: Imprensa Portugueza, 1891.

António Gomes Alves Ferreira é professor da Faculdade de Psicologia e de Ciências da Educação da Universidade de Coimbra. Ex-coordenador da Seção de História da Educação da Sociedade Portuguesa de Ciências da Educação.

antonio@ci.uc.pt

José G. Gondra é professor adjunto e integrante do Programa de Pós-Graduação em Educação da Universidade Estadual do Rio de Janeiro (UERJ). Ex-coordenador do Grupo de Trabalho de História da Educação da Associação Nacional de Pós-Graduação e Pesquisa em Educação (ANPEd).

gondra@oi.com.br

Recebido em 20 de abril de 2006.

Aprovado em 26 de maio de 2006. 